\title{
Preferences of Pinus Sylvestris Seedling Roots for Different Phosphorus Sources under Phosphorus- Deficient Conditions
}

Kaiyu Lei ( $\sim$ kaiyulei097@gmail.com )

University of Amsterdam

Hamish Creber

The University of Edinburgh

Roland Bol

University of Amsterdam

Saran P. Sohi

The University of Edinburgh https://orcid.org/0000-0003-3207-8665

\section{Research Article}

Keywords: Biochar, roots, phosphorus, rhizosphere, spatial structure

Posted Date: January 19th, 2022

DOI: https://doi.org/10.21203/rs.3.rs-1204702/v1

License: (c) (i) This work is licensed under a Creative Commons Attribution 4.0 International License.

Read Full License 


\section{Abstract}

\section{Purpose}

Phosphorus $(P)$ is a limiting nutrient in many managed forests. To further understand the risks and benefits of biochar as a sustainable $P$ source in forest management, an improved mechanistic understanding of its interactions in root systems is required.

\section{Methods}

A rhizobox experiment was conducted to observe root response of $P$. sy/vestris (Scots pine) seedlings to different biochars in comparison to triple superphosphate (TSP) fertilizer as a P source. Three types of wood-derived biochar were compared: biochar from mixed softwood pellets ("Reference biochar"); from the vascular cambium zone of Picea sitchensis (Sitka spruce) ("VCZ biochar") and from mixed softwood pellets infused with TSP ("Processed biochar"). These alternative types of biochar presented a range of available $\mathrm{P}$ from low to high. The activity of roots in the rhizoboxes was monitored and analyzed using spatial GIS software.

\section{Results}

The total length of $P$. sylvestris roots did not significantly differ between treatments. However, roots showed strong preference for soil proximal to VCZ biochar and strong avoidance to TSP fertilizer. There was a milder avoidance effect for Processed biochar. Different preferences were mainly explained by available P: roots favored a moderate, sustained $P$ source and avoided sources of high available $P$. The avoidance effect can be attributed partially to a considerable drop in soil pH around TSP fertilizer.

\section{Conclusion}

The concentration and duration of $\mathrm{P}$ availability affects the root response of $P$. sylvestris to sources of $\mathrm{P}$. In P-deficient conditions, the development of $P$. sy/vestris roots can be markedly improved by introducing biochar with a certain native $\mathrm{P}$ content.

\section{Introduction}

Phosphorus $(P)$ is a key limiting nutrient in the growth and establishment of seedlings in forest ecosystems. The increasing atmospheric nitrogen $(\mathrm{N})$ deposition and resulting $\mathrm{N}$ accumulation and saturation causes $\mathrm{P}$ to replace $\mathrm{N}$ as the limitation of tree growth (Attiwill and Adams 1993; Crowley et al. 2012). Clear-fell silvicultural systems disrupt $P$ cycling and result in a rapid decline in the $P$-pool by leaching, reducing the available soil P during replanting (Kaila et al. 2014; Nieminen 2003; Rodgers et al. 2010). In a P-deficient situation, a tight $P$ 'recycling system' develops, closing the $P$ cycling loop. This maximizes the use-efficiency of the P pool and sustains the P supply within mature forest systems (Lang et al. 2016). In a mycotrophic forest, a 'recycling system' depends on mycorrhizal fungi as well as root morphological alterations (Attiwill and Adams 1993; Lang et al. 2016). 
Through morphological alteration, plants enhance root hair development and generate denser root clusters (Lambers et al. 2006; Ma et al. 2001) under the control of soil P content and plants' endogenous P status (Neumann et al. 2000). Root clusters capture available P in soils by exudation of carboxylates through an anion channel which increases $P$ availability (Lambers et al. 2013). Mycorrhizal fungi in symbiosis with roots extend the $\mathrm{P}$ depletion zones and accelerate available $\mathrm{P}$ transformation through the excretion of organic acids (Cairney 2011). This is achieved by decomposing complex soil organic matter, which may mitigate P-deficient stresses (Cánovas 2019).

Biochar is the product of biomass thermochemical processes, mainly pyrolysis, and consists of different forms of carbon and nutrients (Sohi et al. 2009). Wood-derived biochar contains comparatively low $P$ when compared to biochar produced from animal wastes and to a lesser extent arable crop residue (Hossain et al. 2020; Zhang et al. 2016). The relatively low P content may limit the agronomic value of wood-derived biochar, particularly when compared with mineral $P$ fertilizers that rapidly deconstruct and solubilize in the soil. The release mechanism of $\mathrm{P}$ from biochar is multifactor-dependent (Qian et al. 2013; Uchimiya et al. 2010). By altering soil properties (Joseph et al. 2021) combined with the self-promotion effect of biochar-carbon (Lehmann et al. 2011), biochar prompts root development (Abiven et al. 2015; Lehmann et al. 2011; Xiang et al. 2017), including pine (Pinus spp.) roots in certain forest systems (Wardle et al. 1998)

Root interaction with the charosphere could be a key factor in plants accessing biochar-derived $\mathrm{P}$ (Chen et al. 2021). The porous structure of unprocessed wood-derived biochar makes it easier for roots and hyphae to penetrate and colonize biochar particles and the high internal and external surface provides greater opportunity for nutrient transfer (Prendergast-Miller et al. 2014). Proliferation of mycorrhizal hyphae inside biochar through cracks and pores intensifies the root development as well as nutrient uptake (Ascough et al. 2010; Hammer et al. 2014; Jaafar et al. 2014; Solaiman et al. 2010).

The present study investigates biochar as a sustainable fertilizer for seedling establishment in P-deficient forest ecosystems and investigates the interaction between the charosphere and rhizosphere. Our study tests the hypotheses that (a) seedling root systems develop different morphology according to sources of $P$; and (b) the acquisition of $P$ determines the spatial distribution of new root growth in the early establishment phase.

\section{Material And Methods}

Three types of biochar were assessed as $P$ sources in $P$. sylvestris seedling establishment alongside mineral $\mathrm{P}$ fertilizer. The response of $P$. sylvestris root systems to the presence of three biochars of increasing $P$ content and availability was assessed for low-P conditions using rhizoboxes (Fig. 1) and a bespoke growing medium (Table $1 \mathrm{~b}$ ). Root system response to the biochars was compared to their response to mineral $\mathrm{P}$ fertilizer.

\section{Biochar Production And Properties}


The three biochars were low in P ("Reference biochar"), naturally high in P ("VCZ biochar"), and artificially enhanced in $\mathrm{P}$ ("Processed biochar"). All three biochars used were derived from woody biomass feedstock and produced by the UK Biochar Research Centre (UKBRC) (University of Edinburgh, Edinburgh, UK). The equipment used was the Stage III system, a horizontal continuous feed pyrolysis kiln, manufactured by Ansac Pvt Ltd (Bunbury, Australia). The feedstock was pyrolyzed at a nominal highest heating temperature (HTT) of $550 \pm 5^{\circ} \mathrm{C}$ with a heating rate of $78^{\circ} \mathrm{C} \mathrm{min}{ }^{-1}$. Mean residence time in the kiln was 12 min, with 3.9 min at HTT. Details of the Stage III pyrolysis system can be found in Mašek et al. (2018).

Feedstock for VCZ biochar comprised $40 \%$ wood and $60 \%$ bark by volume, incorporating the vascular cambium zone of Picea sitchensis (Sitka spruce) and naturally enriched in P (Rathnayake et al. 2021). It is a co-product of debarking during sawmill processing of timber logs and was obtained from the Petersmuir sawmill in south-east Scotland (BSW Ltd, Scotland).

Reference biochar was produced from mixed softwood fuel pellets (Puffin Wood Fuels, Insch, Scotland) using the Stage III pyrolysis described above. The sample represents the standard biochar SWP550 that is available from the UKBRC and widely adopted by the research community (Mašek et al. 2018). For use in this study, the SWP550 biochar was infused in deionized water for 72 hours and fully dried

Processed biochar was created by exposing Reference biochar to dissolved $\mathrm{P}$ at a concentration of $410 \mathrm{~g}$ total $\mathrm{P} \mathrm{I}^{-1}$ with TSP fertilizer ( $90 \%$ water soluble $\left.\mathrm{P}\right)$. The infusion was undertaken at a volume ratio of biochar in $\mathrm{P}$ solution and period of 72 hours and fully dried. The $\mathrm{P}$ solution was prepared using commercial TSP fertilizer (Progreen Ltd, Bourne, England).

The composition and properties of the three biochars and TSP fertilizer are shown alongside those of the growing medium used in the rhizoboxes in Table 1.

Table 1 Key chemical properties of (a) supply treatment materials and (b) growing medium/treatment mix in rhizobox treatment areas. Values are mean $\pm S D, n=3$ in a and $b$ except for the Blank, $n=5$.

a) 


\begin{tabular}{|c|c|c|c|c|}
\hline Treatments & VCZ biochar & Reference biochar & Processed biochar & TSP fertilizer \\
\hline $\mathrm{pH}$ & $10.0 \pm 0.01$ & $7.42 \pm 0.02$ & $3.60 \pm 0.02$ & $2.74 \pm 0.40$ \\
\hline $\mathrm{NH}_{4}{ }^{+}-\mathrm{N}\left(\mathrm{mg} \mathrm{g}^{-1}\right)$ & $<0.01$ & $<0.01$ & $0.401 \pm 0.09$ & $1.12 \pm 0.11$ \\
\hline $\mathrm{NO}_{3}^{-}-\mathrm{N}\left(\mathrm{mg} \mathrm{g}^{-1}\right)$ & $<0.02$ & $<0.02$ & $0.08 \pm 0.01$ & $0.722 \pm 0.050$ \\
\hline Available P $\left(\mathrm{mg} \mathrm{g}^{-1}\right)$ & $2.24 \pm 0.84$ & $0.542 \pm 0.010$ & $258 \pm 6$ & $602 \pm 3$ \\
\hline $\mathrm{Fe}\left(\mathrm{mg} \mathrm{kg}^{-1}\right)$ & $22.9 \pm 11.3$ & $66.4 \pm 5.7$ & $29.1 \pm 0.5$ & $189 \pm 3$ \\
\hline $\mathrm{Al}\left(\mathrm{mg} \mathrm{kg}^{-1}\right)$ & $21.4 \pm 10.4$ & $42.4 \pm 3.6$ & $148 \pm 8$ & $387 \pm 6$ \\
\hline $\mathrm{Ca}\left(\mathrm{g} \mathrm{kg}^{-1}\right)$ & $12.4 \pm 5.0$ & $2.71 \pm 0.05$ & $19.7 \pm 0.5$ & $53.2 \pm 0.9$ \\
\hline $\mathrm{Cd}\left(\mathrm{mg} \mathrm{kg}^{-1}\right)$ & $0.06 \pm 0.01$ & $0.05 \pm 0.01$ & $1.49 \pm 0.04$ & $7.61 \pm 0.20$ \\
\hline
\end{tabular}

b)

\begin{tabular}{|c|c|c|c|c|c|}
\hline Treatments & Blank & VCZ biochar & $\begin{array}{l}\text { Reference } \\
\text { biochar }\end{array}$ & $\begin{array}{l}\text { Processed } \\
\text { biochar }\end{array}$ & $\begin{array}{l}\text { TSP } \\
\text { fertilizer }\end{array}$ \\
\hline $\mathrm{pH}$ & $\begin{array}{l}4.41 \pm \\
0.02 c\end{array}$ & $\begin{array}{l}8.12 \pm \\
0.01 \mathrm{a}\end{array}$ & $5.58 \pm 0.01 b$ & $3.65 \pm 0.02 d$ & $2.9 \pm 0.02 \mathbf{e}$ \\
\hline $\mathrm{NH}_{4}^{+}-\mathrm{N}\left(\mathrm{mg} \mathrm{g}^{-1}\right)$ & $\begin{array}{l}1.41 \pm \\
0.06 \mathbf{a}\end{array}$ & $\begin{array}{l}0.798 \pm \\
0.047 b\end{array}$ & $0.742 \pm 0.031 b$ & $0.754 \pm 0.087 b$ & $1.12 \pm 0.11 \mathrm{a}$ \\
\hline $\mathrm{NO}_{3}{ }^{-}-\mathrm{N}\left(\mathrm{mg} \mathrm{g}^{-1}\right)$ & $\begin{array}{l}1.04 \pm \\
0.02 \mathbf{a}\end{array}$ & $\begin{array}{l}0.654 \pm \\
0.029 b\end{array}$ & $0.423 \pm 0.044 c$ & $0.201 \pm 0.009 d$ & $\begin{array}{l}0.722 \pm \\
0.053 b\end{array}$ \\
\hline $\begin{array}{l}\text { Available P (mg } \\
\mathrm{g}^{-1} \text { ) }\end{array}$ & $\begin{array}{l}0.046 \pm \\
0.020 \mathbf{e}\end{array}$ & $1.24 \pm 0.86 c$ & $0.314 \pm 0.048 d$ & $156 \pm 24 b$ & $590 \pm 37 a$ \\
\hline $\mathrm{Fe}\left(\mathrm{mg} \mathrm{kg}^{-1}\right)$ & $64.9 \pm 3.0 b$ & $20.8 \pm 1.2 c$ & $8.91 \pm 0.23 d$ & $23.5 \pm 1.2 \mathrm{c}$ & $173 \pm 4 a$ \\
\hline $\mathrm{Al}\left(\mathrm{mg} \mathrm{kg}^{-1}\right)$ & $\begin{array}{l}9.52 \pm \\
0.54 d\end{array}$ & $15.6 \pm 0.5 c$ & $11.2 \pm 0.4 \mathbf{d}$ & $107 \pm 8 b$ & $365 \pm 2 a$ \\
\hline $\mathrm{Ca}\left(\mathrm{g} \mathrm{kg}^{-1}\right)$ & $\begin{array}{l}0.135 \pm \\
0.007 e^{-}\end{array}$ & $4.72 \pm 0.19 c$ & $1.21 \pm 0.03 d$ & $11.2 \pm 0.7 b$ & $50.2 \pm 1.0 \mathbf{a}$ \\
\hline $\mathrm{Cd}\left(\mathrm{mg} \mathrm{kg}^{-1}\right)$ & $\begin{array}{l}0.04 \pm \\
0.01 \mathrm{c}\end{array}$ & $0.06 \pm 0.01 c$ & $0.05 \pm 0.01 c$ & $1.11 \pm 0.04 b$ & $7.12 \pm 0.33 a$ \\
\hline
\end{tabular}

Rhizobox Experiment Design 
Rhizoboxes were made of $0.6 \mathrm{~cm}$ thickness PVC sheet. The effective size was $40 \mathrm{~cm}$ height $x 30 \mathrm{~cm}$ width $\times 0.6 \mathrm{~cm}$ thick (Fig. 1). The separation was customized for one-year-old $P$. sy/vestris seedlings, considering the diameter of the stem and the length and density of their root systems. The rhizobox comprised five parts in total including the sides and base, which had machined groves along joins to provide additional strength and prevent potential slippage. The transparent front sheet was detachable and designed for observation and photographic imaging. Black opaque sheets were used for the other sides and were fixed along the exterior of the joins using polyurethane grab adhesive (Gorilla Glue Co., Sharonville, Ohio). Rhizoboxes were set for 24 hours and designed to prevent ingress of light and maintain consistent conditions inside and outside the rhizoboxes. Following the completion of assembling, they were rinsed, alcohol-sterilized and dried before use.

Bespoke growing medium was prepared and sterilized 2 weeks prior to the set-up. It comprised of $60 \%$ peat and $40 \%$ quartz sand by volume, which ensured key nutrients were initially at deficient level (Table 1a). The growing medium had no nutrients added and displayed nutrient status comparable to particularly poor forest soil (Pyatt et al. 2001), accurately reflecting P-limited plantation forests in the UK. The growing medium was passed through a $2 \mathrm{~mm}$ sieve prior to filling the prepared rhizoboxes. Approximately $720 \mathrm{~g}$ of growing medium was added into each rhizobox. The variation of added growing medium was no more than $10 \%$ to maintain a bulk density of $1 \pm 0.1 \mathrm{~kg} \mathrm{~m}^{-3}$ to ensure a comparable growing environment from the outset. If the measured $\mathrm{pH}$ (McLean 1983) of growing medium was outside the range $4.5 \pm 0.5$ it was adjusted using $0.01 \mathrm{~mol} \mathrm{I}^{-1} \mathrm{NaOH}$ solution and $0.01 \mathrm{~mol} \mathrm{I}^{-1} \mathrm{H}_{2} \mathrm{SO}_{4}$. The growing medium in the rhizoboxes was fully watered with deionized water and stabilized for 48 hours before the seedlings were planted.

The $30 \mathrm{~cm} \times 40 \mathrm{~cm}$ frontal area of the rhizoboxes were divided into twelve unit-sectors with a size of 10 $\mathrm{cm}$ width $\times 10 \mathrm{~cm}$ height which were marked onto the front sheet to create a visual grid. The four treatment materials were applied at differential mass dose after the growing medium was fully stabilized based on the recommended dose of P fertilization for conifer seedlings in P-deficient soils (Taylor 1991) (adjusted for targets application and growing medium volume, to maintain equivalent TSP : growing medium by volume): $0.96 \mathrm{~g}$ TSP fertilizer, $4.56 \mathrm{~g}$ Processed biochar. $3.60 \mathrm{~g}$ Reference biochar and $3.60 \mathrm{~g}$ VCZ biochar. All biochar treatments had equal mass dose of biochar, with processed biochar having additional biochar due to TSP infusion of equal dry weight of TSP to TSP treatment. The treatments were applied centrally in the lower left sector without any mesh exclusion. The treatment area (TA) for each treatment was $2 \mathrm{~cm}, 4 \mathrm{~cm}, 5.5 \mathrm{~cm}$ and $7.8 \mathrm{~cm}$, respectively using prepared paper templates. The same volume of growing medium (1:1) was introduced to ensure the bulk density approximately the same between different treatments. Each treatment was arranged with five replicates. A blank control ("Blank") comprising growing medium was included, resulting in 25 rhizoboxes in total.

One-year-old container grown $P$. sy/vestris seedlings were obtained from Forest Research (Northern Research Station, Roslin, Scotland) as P. sylvestris is the most tolerant and suitable conifer species in 
sandy P-deficient soils with highest commercial profits. These trees had been grown from seed and all seedlings were in a dormant state. The seedlings had all been grown using the same growing medium and all displayed root systems $20-30 \mathrm{~cm}$ in length and were not nutrient deficient. Seedlings were carefully removed from containers and growing medium was manually removed from the root systems. They were carefully rinsed to avoid transfer of nutrients from the original growing medium. The seedlings were planted into the rhizoboxes approximately at a central position, gently separating entangled roots. To diminish the possibility of 'transplant shock', roots were not sterilized or trimmed. To ensure roots could consistently detect those $P$ sources, one root in each rhizobox was positioned $2 \mathrm{~cm}$ adjacent to the edge of the TA, oriented towards the center. Each rhizobox was watered weekly by removing the front sheet and evenly spraying the surface medium with distilled water using a mist sprayer. The watering regime was flexible to ensure that the growing medium was moist but with no excess water or vertical water movement or pooling.

The front (colorless) PVC sheets were clipped to the treated, planted boxes. Polystyrene sheets cut to the same size and shape were used to exclude light and maintain consistent internal conditions. They were also used to loosely cover the surface of the growing medium to reduce soil surface light penetration and temperature gradients, while ensuring respiration was not impeded. The temperature and relative humidity in the glasshouse was between $17.0-27.2^{\circ} \mathrm{C}$ and $36.5-100.0 \%$, respectively during the 10 weeks experimental period. Due to space limited, 10 weeks later, interior surfaces were fully covered by roots and new roots started to generate towards deeper growing medium.

The experiment used a randomized block design, with one replicate of each treatment randomly placed in each block. The rhizoboxes in each block were stacked together at an angle of $60^{\circ}$, taking care to ensure the branches of above-ground parts did not interfere and were horizontal and vertically staggered (Fig. 1).

\section{Morphological Monitoring And Analysis Of Root Growth}

The root system in each rhizobox was imaged photographically once each week. A lightbox was constructed from PVC sheet enveloped with thick photographic curtain. A port was created at the top of the box to provide access for a camera lens. The box was illuminated internally with LED symmetrical lighting strips orientated in four evenly distributed parallel lines across the top of the box, while thick black felt was used to line the base and sides to eliminate the ingress of natural light. The rhizoboxes were imaged in turn, with a fixed camera position in the light sealed port and with a precisely determined position for the rhizobox that ensured consistency in image positions. The rhizoboxes were imaged weekly using a SLR camera at a native resolution of 7360 x 4912 pixels.

A method to spatially track and analyze root growth was developed using ArcGIS Pro 2.6 software (ESRI, Redlands, USA). The first step was to map each image to a georeferenced $30 \mathrm{~cm} \times 40 \mathrm{~cm}$ physical area (the effective rhizobox area). This provided the geographic coordination required for ArcGIS Pro 2.6 to define absolute position. A feature layer was then created to manually track growth of individual roots, assisted by the association between root color and increasing root age. New roots develop on the interior 
surface of the PVC owing to geotropism and the availability of water and air. Only new roots growing on the interior surface were taken into account.

Weekly images were analyzed as separate segments for the same rhizobox image. Overlaying the images in this way allowed an integrated root growth feature layer to be created and summarized for each rhizobox. This provided the calculated length and density of cumulative root growth. The analysis also allowed length, density and growth rate to be visualized and analyzed. Root growth was separately assessed for the whole rhizobox, TA and TA3.

\section{Sampling And Chemical Analysis}

10 weeks later, the root system was separated from the seedling at the first root branch and was gently rinsed, dried in an oven at $90^{\circ} \mathrm{C}$ and weighed on an electronic balance (accurate to $0.001 \mathrm{~g}$ ). New needles were picked individually from the top and oven dried at $90^{\circ} \mathrm{C}$ before further total $\mathrm{P}$ analysis.

Growing medium, treatment materials and treatment area (mix of treatment materials and growing medium, TA), were sampled at the beginning before the seedlings were introduced and were pooled across replicates for chemical analysis (Table 1b). After 10 weeks the TA and the growing medium in each rhizobox were separately sampled, using prepared paper templates to ensure precise positioning. The material sampled within each area was then thoroughly mixed to reduce intra-sample area variation and transferred to a refrigerator below $4^{\circ} \mathrm{C}$. Samples were oven dried at $90^{\circ} \mathrm{C}$ and were ground in a ball grinder before further analysis.

Chemical analysis was undertaken to determine available $\mathrm{P}$ and total $\mathrm{P}, \mathrm{Fe}, \mathrm{Al}, \mathrm{Ca}$ and other heavy metals to elucidate potential factors influencing root-biochar interactions. Extraction or digestion procedure for each sample was replicated for 3 times. Available P of samples was analyzed through water extraction (Prendergast-Miller et al. 2014) and subsequent analysis of the extracts by autoanalyzer (Bran Luebbe AA3, Seal Analytical, Norderstedt, Germany). Total P, Fe, Al, Ca and other heavy metals were extracted by a modified dry-ash method for biochar and measured by inductively coupled plasma optical emission spectrometry (ICP-OES, Thermo-iCAP 6300, Thermo Electron, Waltham, USA). Samples were heated in a muffle furnace $\left(500^{\circ} \mathrm{C}, 8 \mathrm{~h}\right)$ and placed into a steam bath upon cooling. Concentrated nitric acid $\left(\mathrm{HNO}_{3}\right)$ was added and evaporated to dryness, followed by $1: 4 \mathrm{HNO}_{3}$ and $\mathrm{H}_{2} \mathrm{O}_{2}$ which was evaporated to dryness. All residues were transferred through Whatman Grade 4 filter paper, using $\mathrm{HNO}_{3}$ and deionized water, into a volumetric flask. The elemental composition of the filtrate was analyzed using inductively ICP-OES. The $\mathrm{pH}$ of growing medium was assessed for the zone within $3 \mathrm{~cm}$ of treatment area (TA3). This was done after 10 weeks plant growth using a soil : water ratio of 1:2 (McLean 1983).

\section{Data analysis}

ArcGIS Pro 2.6 software was used for initial length and density calculation of new roots and then transferred to point features for kernel density analysis which can reflect the density of roots in the 
neighborhood of each output raster cell. pH data was tested for normality (K-S test) and homogeneity of variance (Levene test, $p=0.05$ ). One-way analysis of variance (ANOVA) was conducted using Python 3.8 and with $p=0.05$ as the threshold for statistical significance. Linear and nonlinear LangmuirEXT1 regression models were developed using Origin Pro 2018 statistical software (Origin Lab, Northampton, USA).

\section{Results}

\section{Root morphological responses to different treatment materials}

After 10 weeks, there was no statistically significant effect of treatment material on total growth of new roots or total root biomass (root dry weight). One seedling in the Blank rhizoboxes did not survive transplanting and this replicate was excluded from further analyses. All roots within $2 \mathrm{~cm}$ of TSP TA exhibited complete death of root tissues. Similar root mortality was found in one rhizobox where the treatment patch contained Processed biochar.

Linear regression revealed similar growth trends of roots between the Blank and VCZ biochar after 10 weeks. Root growth in Reference biochar treatments was slightly lower than the Blank, but much higher than Processed biochar or TSP. In TA3, root growth was considerably greater for rhizoboxes with TA containing Reference biochar or VCZ biochar. Considering the distribution of residual values, a nonlinear LangmuirEXT1 model was adopted for (Fig. 2). All treatments showed a slow growth rate at the beginning of the experiment (weeks 0 - 4), followed by a stable elevated growth rate (weeks 5 - 10), with strong fit to the nonlinear LangmuirEXT1 model. Total root growth showed indications of slowing in some treatments. The degree of rapid growth varied between different treatments. Reference biochar and VCZ biochar treatments showed relatively better growth at the beginning but slowed down in the final weeks while Processed biochar and TSP fertilizer treatments had much worse root growth. The limitations of nutrients and spaces in the rhizoboxes preclude prediction. In TA3 (Fig. 2b), the root growth for Reference biochar and VCZ biochar treatments was consistent with the overall trend and much better for Processed biochar and TSP fertilizer treatments. Root growth for Processed biochar and TSP fertilizer was at a consistent, extremely low level. It indicates that the root growth for TA3 in Reference biochar and VCZ biochar treatments was greater than other treatments prior to Week 8 , which may indicate P foraging by seedling roots.

According to model fitting results (Fig. 2) as well as Kernel Density analysis results (Fig. 3), P. sy/vestris roots have a distinct growth preference for VCZ biochar TA. The root density in the 10th week in the VCZ TA and TA3 were $4.2 \mathrm{~mm} \mathrm{~cm}^{-2}$ and $4.1 \mathrm{~mm} \mathrm{~cm}^{-2}$ greater than the Blank, respectively. TA in TSP fertilizer showed clear reduction in root density, with complete absence of root growth in most cases. A similar but milder reduction was observed in Processed biochar. $P$. sylvestris roots show undifferentiated growth in the Blank. It was notable that the area of densest root growth for VCZ biochar was located at the boundary of treated areas and that root density was significantly higher than the same areas in the Blank. 
In the early weeks, there was no significant difference of root density between treatments in TA3. Over time, a significant difference emerged between TSP fertilizer and Reference biochar treatments. The divergence increased until the final week, when significant differences between TSP fertilizer and all of the other treatments emerged.

By comparing root density in TA3 with the corresponding area on the opposite side of the rhizoboxes, a quantitative left-to-right comparison can made throughout the experimental period for each treatment (Fig. 4). During the first 7 weeks, there was no significant preference for roots associated with any TA, although avoidance of TSP was visually apparent. From week 8, the left-to-right comparison became significant for TSP fertilizer and VCZ biochar treatments. Subsequently, from week 8 , the trends began to clearly diverge (Fig. 4). In VCZ biochar and Reference biochar treatments, root growth became concentrated within their TA indicating the emergence of preference. Conversely, an avoidance emerged in Processed biochar and TSP fertilizer treatments. In the Blank, a weak avoidance emerges at the beginning, but convergence on a left-to-right difference around 0 indicates that the contribution of new roots in the Blank gradually becomes uniform and undifferentiated (Fig. 4). Overall, the differences demonstrate that there was a strong preference for $P$. sylvestris roots to forage around VCZ biochar and a milder corresponding preference for Reference biochar. There was a strong avoidance for TSP fertilizer and a milder avoidance for Processed biochar. Around Processed biochar, a high-density of new roots were concentrated on the outer edge of the TA (Fig. 3).

\section{Roots Response To Different Ph}

The growing medium was alkalized by VCZ biochar and Reference biochar, and acidified by Processed biochar and TSP fertilizer (Table 1b). After 10 weeks, $\mathrm{pH}$ in areas within $3 \mathrm{~cm}$ of the TA stabilized between 5.2 to 6.2, with pH 5.7 - 6.2 inTA3 of the Blank, VCZ biochar and Reference biochar treatments, and $\mathrm{pH} 5.2$ to 5.7 in TA3 of Processed biochar and TSP fertilizer treatments. The difference between the Blank and both Processed biochar and TSP fertilizer was significant, even in areas at a greater distance $(4.5 \mathrm{~cm})$ from TA3. However, no distinct relationship between $\mathrm{pH}$ and root growth was found.

\section{Roots Response To Different Available P}

The available $\mathrm{P}$ in TA ranged from extremely low in the Blank to extremely high in TSP fertilizer treatments. TSP fertilizer has extremely high available $\mathrm{P}$ (and low $\mathrm{pH}$ ) that caused root mortality and the evidence of strong avoidance.

Regardless of source, the $\mathrm{P}$ available in TA declined drastically after 10 weeks (Fig. 5a). Proportional available $P$ reduction was not significantly different between TSP fertilizer, Processed biochar and Reference biochar, while the difference between the Blank and other treatments was significant. The VCZ biochar treatment showed the lowest proportional reduction (92.3\%) in available P over the duration of the experiment (apart from the Blank, where the reduction was 44\%). The reduction rate for VCZ biochar 
is significantly lower than in TSP fertilizer treatments (97.9\%). The mean reduction rate in Reference biochar and Processed biochar treatments are $95.6 \%$ and $96.1 \%$, respectively.

There was significantly higher $\mathrm{Ca}$, Fe and Al in TA when the P source was TSP fertilizer (Fig. 5b). The Fe and Al content of VCZ biochar was lower than TSP fertilizer, but similar to that of Reference biochar, though the release of Fe from Reference biochar and from Processed biochar was impeded. Processed biochar showed a significantly higher Al content than that of the Blank.

The total $\mathrm{P}$ content in new growth leader needles can reflect the $\mathrm{P}$ uptake in the past few months and indicate seedling $\mathrm{P}$ deficiency. Total $\mathrm{P}$ content in new growth leader needles for TSP fertilizer treatments was significantly higher than the Blank and VCZ biochar treatments. There was no significant difference in this parameter between the Blank and VCZ biochar or Reference biochar.

\section{Discussion}

The results showed that $P$. sylvestris seedlings developed root morphology that were distinct with respect to $\mathrm{P}$ sources. The morphological root response in the acquisition of $\mathrm{P}$ from different sources determines the spatial distribution of new root growth in the early establishment phase. There are several potential mechanisms to account for these differences, which either enhance or limit root development.

\section{Morphological And Spatial Root Responses To Sources Of Phosphorus}

The length, angle and diameter of roots are known to be affected by many factors, including aoil nutrient content (López-Bucio et al. 2003), pH (Hinsinger et al. 2003) and soil physical structure (Dexter 2004). Some effects of P-deficient conditions are the stimulation of primary root growth and the exploration of a larger soil volume (Ma et al. 2001). Roots under these conditions may also exude carboxylates to facilitate the mobilization of $\mathrm{P}$ (Lambers et al. 2013). In the present study, the roots of $P$. sy/vestris showed clear preference for VCZ biochar compared to the Blank, and a milder preference for Reference biochar. These preferences likely reflect the deliverable $\mathrm{P}$ content of the biochar. Mineral nutrients associated with the interior and exterior surfaces of biochar may be mobilized by exposure to soil solution, providing a supply of assimilable $P$ in otherwise deficient soils (Joseph et al. 2021). Phosphorus in biochar originates from the feedstock biomass and in general, displays low concentrations. The vascular cambium has a higher concentration, extending to the zones used to create the VCZ biochar from Picea sitchensis (Sitka spruce) biomass.

Root aggregation occurs around the boundary of the VCZ biochar TA, suggesting that VCZ biochar could provide sufficient $P$ to seedlings. VCZ biochar concentrated root development in TA and limited foraging in areas that are low in P. Antithetical to VCZ biochar, Reference biochar provided low available P, resulting in a sparser but wider root system in order to satisfy $\mathrm{P}$ demand. 
Alteration of soil pH can result in phosphorus fixation, where $\mathrm{Al}, \mathrm{Fe}$ and $\mathrm{Ca}$ competitively bind to free phosphate compounds, decreasing the $\mathrm{P}$ that is available in soils (Schlesinger 2005). The $\mathrm{P}$ pool in the Blank was probably at equilibrium with respect to $\mathrm{pH}$, whereas TSP lowered $\mathrm{pH}$ and likely resulted in rapid reduction of available P (Penn and Camberato 2019) (Fig. 5a). Although acidic conditions have a negative long-term impact on $\mathrm{P}$ acquisition provision in a forest system, extremely high available $\mathrm{P}$ can directly inhibit root growth and potentially cause root mortality (Ma et al. 2001). Where TSP fertilizers guarantee $\mathrm{P}$ supply for $P$. sylvestris, the concentration of $\mathrm{P}$ can still inhibit wider foraging, leading to root structures that are detrimental to mature stands.

Different biochars differently affected the $\mathrm{pH}$ of the external growing medium, but the external $\mathrm{pH}$ will have also affected the availability of the $P$ present in different amounts in different biochars. These factors interact to determine the $P$ that is available inside and around biochar TA. High levels of Ca could limit the release of $P$ from the high-pH interior of $V C Z$ and Reference biochar (Buss et al. 2018). The proportional decrease in available P from VCZ biochar treatments was, however, significantly smaller than for TSP fertilizer. The $\mathrm{pH}$ conditions at the interface of alkaline biochar and acidic growing medium could be critical, providing for mobilization of $\mathrm{P}$ associated with $\mathrm{Ca}$ but without impedance by Fe that form below $\mathrm{pH} \sim 6$ (Penn and Camberato 2019). It is likely that the availability of $\mathrm{P}$ was affected indirectly by $\mathrm{pH}$, altering the labile $\mathrm{P}$ pool in the growing medium and the total $\mathrm{P}$ released from TA. Comparison of root biomass in TA of contrasting $\mathrm{pH}$ revealed no significant difference, suggesting that direct effects of $\mathrm{pH}$ were not a major factor.

In addition to the chemical mobilization of $\mathrm{P}$ that occurs along a pH gradient, physical changes could be relevant. VCZ biochar is friable, has a low bulk density, high porosity and a large internal surface area (Rathnayake et al. 2021), This supports relatively easy access by roots and ectomycorrhizal fungi that facilitate $P$ acquisition. The folding and compression that occurs in the pelleting of biomass used to make Reference biochar and Processed biochar creates structures that are less conducive to such interactions. Surface colonization by ectomycorrhizal fungi was visually apparent on VCZ and Reference biochar. These fungi could be an alternative mycotrophic path for the access and acquisition of $\mathrm{P}$ by $P$. sylvestris (Joseph et al. 2021). On the other hand, the potential for these organisms to assist in the uptake of $P$ within the timeframe of the rhizobox study is uncertain.

Analysis for metals revealed concentrations of Cd in TSP fertilizer that could potentially limit the root growth and lead to levels of $\mathrm{Cd}$ in plant tissue that present toxicity issues (Yazici et al. 2021). Although direct toxic effects on $P$. sy/vestris root systems and above-ground depends on the free $\mathrm{Cd}^{2+}$ concentration in plant tissues, which was not analyzed, the Cd concentration measured in TSP fertilizer was approximately an order of magnitude higher than thresholds set for fertilizer products in the Netherlands $\left(7 \mathrm{mg} \mathrm{kg}^{-1}\right.$ ) (Crommentuijn et al. 2000). It similarly exceeds the $5 \mathrm{mg} \mathrm{kg}^{-1}$ threshold proposed by Ismael et al. (2019). Since most of the P added in Processed biochar originated from TSP, it was not surprising that concentrations of $\mathrm{Cd}$ were also in excess of the thresholds above.

Potential of biochar in phosphorus management in temperate forest systems

Page $12 / 19$ 
The available $P$ is of critical to establishment success in the first stage of forest regeneration (Ceccon et al. 2003) and is often the limiting factor during seedling establishment in sandy upland planting sites in the UK. P. sy/vestris is widely planted in semi-natural and commercial forests (Savill 2019) as a tolerant species that can survive and grow in nutrient poor sandy soils where other species would be unsuitable. Seedling root development is important as it influences the root architecture of the mature tree, with high lateral root growth of seedlings improving tree stability and growth. Wind damage is the primary factor in determining the terminal height of trees in Scotland and limits the silvicultural management options. Improved crop stability is vital to sustainable forest management in the UK.

Biochar has been recognized as an option in the management of agricultural soils in the UK (Dobbie et al. 2011). The specific use of biochar in silviculture has not yet been widely considered. The results of the present study indicate that biochar can be selected to efficiently deliver small doses of $\mathrm{P}$ to growing seedlings, manipulating $\mathrm{pH}$ in the charosphere and stimulating symbioses with fungi. Indeed, VCZ biochar has similar available $\mathrm{P}$ and porous structure to charcoal collected in coniferous forests after wildfires (Gundale and DeLuca 2007; Santín et al. 2017) and Wardle et al. (1998) have demonstrated that charcoal has a significant positive effect on the germination and growth of trees in pine forest. Pinus spp. are generally fire-adapted and other studies have shown a significant improvement of plant growth by applying charcoal derived from wildfires (DeLuca et al. 2006; Gundale and DeLuca 2007).

Co-products of timber processing such as the cambial zone of $P$. sylvestris contain nutrient $P$ that could be re-cycled back into forestry on establishment sites that are nutrient limited. Returning to P-deficient forest soils as a fertilizer assists in closure of the $P$ cycle and contributes to the sustainability of forestry operations. VCZ biochar shows good potential to perform as a sustainable P fertilizer in natural or seminatural coniferous forest systems.

\section{Conclusion}

Growth of roots in Pinus sylvestris seedlings showed strong preference for soil proximal to biochar made from the vascular cambial zone of Picea sylvestris and strong avoidance of TSP fertilizer. The preference and avoidance effects for biochar from softwood pellets with and without infused phosphorus, respectively, were milder. These different preferences reflected the concentration and duration of $\mathrm{P}$ supply available from the materials, which was probably a function of $\mathrm{pH}$ at the soil interface. VCZ biochar has good potential as a source of $\mathrm{P}$ in establishment of forests on P-deficient soils.

\section{Declarations}

\section{Acknowledgements}

I would like to thank Dr. Albert Tietema and Dr. Thijs de Boer from IBED, University of Amsterdam for their suggestions on data analysis. John Morman from the Crew Labs, School of GeoSciences, The University of Edinburgh, helped a lot in chemical analysis, Sophie Haupt, Billy Adams and Pat Watson from the 
School of Biological Sciences glasshouse facility provided supports during the rhizobox experiment and Dr. Ondřej Mašek produced the biochars.

\section{Funding}

This study was supported by IBED, University of Amsterdam and UKBRC, School of GeoSciences, the University of Edinburgh.

\section{Competing interests}

We declare there is no competing financial interest.

\section{Author contributions}

All authors conttributed to the study conception, espically Hamish Creber. The biochars, seedlings and growing medium were prepared by Hamish Creber and Kaiyu Lei. The rhizoboxes were designed and assembled by Hamish Creber and Kaiyu Lei. Specimen collection and analysis was performed by Kaiyu Lei and Hamish Creber. Kaiyu Lei collected and analysed the data and worte the firest draft of the manuscript. All authors commented on previous verisons and did some modifications. All authors read and approved the final manuscript.

\section{Data availability}

The dataset generated during this study are available from the corresponding author on reasonable request.

\section{References}

1. Abiven S, Hund A, Martinsen V, Cornelissen G (2015) Biochar amendment increases maize root surface areas and branching: a shovelomics study in Zambia. Plant Soil 395:45-55. https://doi.org/10.1007/s11104-015-2533-2

2. Ascough PL, Sturrock CJ, Bird MI (2010) Investigation of growth responses in saprophytic fungi to charred biomass. Isotopes Environ Health Stud 46:64-77. https://doi.org/10.1080/10256010903388436

3. Attiwill PM, Adams MA (1993) Nutrient cycling in forests. New Phytol 124:561-582. https://doi.org/10.1111/j.1469-8137.1993.tb03847.x

4. Buss W, Assavavittayanon K, Shepherd JG, Heal KV, Sohi S (2018) Biochar phosphorus release is limited by high ph and excess calcium. J Environ Qual 47:1298-1303. https://doi.org/10.2134/jeq2018.05.0181

5. Cairney JW (2011) Ectomycorrhizal fungi: the symbiotic route to the root for phosphorus in forest soils. Plant Soil 344:51-71. https://doi.org/10.1007/s11104-011-0731-0

6. Cánovas FM (2019) Molecular Physiology and Biotechnology of Trees. Academic Press, San Diego 
7. Ceccon E, Huante P, Campo J (2003) Effects of nitrogen and phosphorus fertilization on the survival and recruitment of seedlings of dominant tree species in two abandoned tropical dry forests in Yucatán, Mexico. For Ecol Manag 182:387-402. https://doi.org/10.1016/S0378-1127(03)00085-9

8. Chen X, Lewis S, Heal KV, Lin Q, Sohi SP (2021) Biochar engineering and ageing influence the spatiotemporal dynamics of soil pH in the charosphere. Geoderma 386:114919. https://doi.org/10.1016/j.geoderma.2020.114919

9. Crommentuijn T, Sijm D, de Bruijn J, van den Hoop M, van Leeuwen K, van de Plassche E (2000) Maximum permissible and negligible concentrations for metals and metalloids in the Netherlands, taking into account background concentrations. J Environ Manage 60:121-143. https://doi.org/10.1006/jema.2000.0354

10. Crowley KF, McNeil BE, Lovett GM et al (2012) Do nutrient limitation patterns shift from nitrogen toward phosphorus with increasing nitrogen deposition across the northeastern United. States? Ecosystems 15:940-957. https://doi.org/10.1007/s10021-012-9550-2

11. DeLuca TH, MacKenzie MD, Gundale MJ, Holben WE (2006) Wildfire-produced charcoal directly influences nitrogen cycling in ponderosa pine forests. Soil Sci Soc Am J 70:448-453. https://doi.org/10.2136/sssaj2005.0096

12. Dexter AR (2004) Soil physical quality: Part I. Theory, effects of soil texture, density, and organic matter, and effects on root growth. Geoderma 120:201-214. https://doi.org/10.1016/j.geoderma.2003.09.004

13. Dobbie KE, Bruneau PMC, Towers W (2011) The State of Scotland's Soil. Natural Scotland. http://www.sepa.org.uk/land/land_publications.aspx

14. Gundale MJ, DeLuca TH (2007) Charcoal effects on soil solution chemistry and growth of Koeleria macrantha in the ponderosa pine/Douglas-fir ecosystem. Biol Fert Soils 43:303-311. https://doi.org/10.1007/s00374-006-0106-5

15. Hammer EC, Balogh-Brunstad Z, Jakobsen I, Olsson PA, Stipp SL, Rillig MC (2014) A mycorrhizal fungus grows on biochar and captures phosphorus from its surfaces. Soil Biol Biochem 77:252260. https://doi.org/10.1016/j.soilbio.2014.06.012

16. Hinsinger P, Plassard C, Tang C, Jaillard B (2003) Origins of root-mediated pH changes in the rhizosphere and their responses to environmental constraints: a review. Plant Soil 248:43-59. https://doi.org/10.1023/A:1022371130939

17. Hossain MZ, Bahar MM, Sarkar B et al (2020) Biochar and its importance on nutrient dynamics in soil and plant. Biochar 2:279-420. https://doi.org/10.1007/s42773-020-00065-z

18. Ismael MA, Elyamine AM, Moussa MG, Cai M, Zhao X, Hu C (2019) Cadmium in plants: uptake, toxicity, and its interactions with selenium fertilizers. Metallomics 11:255-277. https://doi.org/10.1039/c8mt00247a

19. Jaafar NM, Clode PL, Abbott LK (2014) Microscopy observations of habitable space in biochar for colonization by fungal hyphae from soil. J Integr Agr 13:483-490. https://doi.org/10.1016/S20953119(13)60703-0 
20. Joseph S, Cowie AL, Van Zwieten L et al (2021) How biochar works, and when it doesn't: A review of mechanisms controlling soil and plant responses to biochar. GCB Bioenergy 13:1731-1764. https://doi.org/10.1111/gcbb.12885

21. Kaila A, Sarkkola S, Laurén A et al (2014) Phosphorus export from drained Scots pine mires after clear-felling and bioenergy harvesting. Forest Ecol Manag 325:99-107. https://doi.org/10.1016/j.foreco.2014.03.025

22. Lambers H, Clements JC, Nelson MN (2013) How a phosphorus-acquisition strategy based on carboxylate exudation powers the success and agronomic potential of lupines (Lupinus, Fabaceae). Am J Bot 100:263-288. https://doi.org/10.3732/ajb.1200474

23. Lambers H, Shane MW, Cramer MD, Pearse SJ, Veneklaas EJ (2006) Root structure and functioning for efficient acquisition of phosphorus: matching morphological and physiological traits. Ann Bot 98:693-713. https://doi.org/10.1093/aob/mcl114

24. Lang F, Bauhus J, Frossard E et al (2016) Phosphorus in forest ecosystems: new insights from an ecosystem nutrition perspective. J Plant Nutr Soil Sci 179:129-135.

https://doi.org/10.1002/jpln.201500541

25. Lehmann J, Rillig MC, Thies J, Masiello CA, Hockaday WC, Crowley D (2011) Biochar effects on soil biota - A review. Soil Biol Biochem 43:1812-1836. https://doi.org/10.1016/j.soilbio.2011.04.022

26. López-Bucio J, Cruz-Ramırez A, Herrera-Estrella L (2003) The role of nutrient availability in regulating root architecture. Curr Opin Plant Biol 6:280-287. https://doi.org/10.1016/S1369-5266(03)00035-9

27. Ma Z, Bielenberg DG, Brown KM, Lynch JP (2001) Regulation of root hair density by phosphorus availability in Arabidopsis thaliana. Plant Cell Environ 24:459-467. https://doi.org/10.1046/j.13653040.2001.00695.x

28. Mašek O, Buss W, Roy-Poirier A et al (2018) Consistency of biochar properties over time and production scales: A characterisation of standard materials. J Anal Appl Pyrol 132:200-210. https://doi.org/10.1016/j.jaap.2018.02.020

29. McLean EO (1983) Soil pH and lime requirement.. In: In: Page AL (ed) Methods of soil analysis: Part 2 Chemical and microbiological properties, 2nd edn. American Society of Agronomy, Soil Science Society of America, Madison, pp 199-224

30. Neumann G, Massonneau A, Langlade N, Dinkelaker B, Hengeler C, Römheld V, Martinoia E (2000) Physiological aspects of cluster root function and development in phosphorus-deficient white lupin (Lupinus albus L.). Ann Bot 85:909-919. https://doi.org/10.1006/anbo.2000.1135

31. Nieminen M (2003) Effects of clear-cutting and site preparation on water quality from a drained Scots pine mire in southern Finland. Boreal Environ Res 8:53-59

32. Penn CJ, Camberato JJ (2019) A critical review on soil chemical processes that control how soil pH affects phosphorus availability to plants. Agriculture 9:120. https://doi.org/10.3390/agriculture9060120

33. Prendergast-Miller MT, Duvall M, Sohi SP (2014) Biochar-root interactions are mediated by biochar nutrient content and impacts on soil nutrient availability. Eur J Soil Sci 65:173-185. 
https://doi.org/10.1111/ejss.12079

34. Pyatt G, Ray D, Fletcher J (2001) An Ecological Site Classification for Forestry in Great Britain. Bulletin 124. Forestry Commission, Edinburgh

35. Qian T, Zhang X, Hu J, Jiang H (2013) Effects of environmental conditions on the release of phosphorus from biochar. https://doi.org/10.1016/j.chemosphere.2013.07.041. Chemosphere 93:2069-2075

36. Rathnayake D, Creber H, Van Poucke R, Sohi SP, Meers E, Mašek O, Ronsse F (2021) Biochar from sawmill residues: characterization and evaluation for its potential use in the horticultural growing media. Biochar 3:201-212. https://doi.org/10.1007/s42773-021-00092-4

37. Rodgers M, O'Connor M, Healy MG et al (2010) Phosphorus release from forest harvesting on an upland blanket peat catchment. For Ecol Manag 260:2241-2248. https://doi.org/10.1016/j.foreco.2010.09.037

38. Santín C, Doerr SH, Merino A et al (2017) Carbon sequestration potential and physicochemical properties differ between wildfire charcoals and slow-pyrolysis biochars. Sci Rep 7:11233. https://doi.org/10.1038/s41598-017-10455-2

39. Savill PS (2019) The silviculture of trees used in British forestry, 3rd edn. CABI, Boston

40. Schlesinger WH (2005) Biogeochemistry. Elsevier, Amsterdam

41. Sohi S, Lopez-Capel E, Krull E, Bol R (2009) Biochar, climate change and soil: A review to guide future research. CSIRO Land and Water Science Report 5:17-31

42. Solaiman ZM, Blackwell P, Abbott LK, Storer P (2010) Direct and residual effect of biochar application on mycorrhizal root colonisation, growth and nutrition of wheat. Soil Res 48:546-554

43. Taylor CMA (1991) Forest Fertilisation in Britain. Forestry Commission, London

44. Uchimiya M, Lima IM, Klasson KT, Wartelle LH (2010) Contaminant immobilization and nutrient release by biochar soil amendment: roles of natural organic matter. Chemosphere 80:935-940. https://doi.org/10.1016/j.chemosphere.2010.05.020

45. Wardle DA, Zackrisson O, Nilsson MC (1998) The charcoal effect in Boreal forests: mechanisms and ecological consequences. Oecologia 115:419-426. https://doi.org/10.1007/s004420050536

46. Xiang Y, Deng Q, Duan H, Guo Y (2017) Effects of biochar application on root traits: a meta-analysis. GCB Bioenergy 9:1563-1572. https://doi.org/10.1111/gcbb.12449

47. Yazici MA, Asif M, Tutus Y, Ortas I, Ozturk L, Lambers H, Cakmak I (2021) Reduced root mycorrhizal colonization as affected by phosphorus fertilization is responsible for high cadmium accumulation in wheat. Plant Soil 468:19-35. https://doi.org/10.1007/s11104-021-05041-5

48. Zhang H, Chen C, Gray EM, Boyd SE, Yang H, Zhang D (2016) Roles of biochar in improving phosphorus availability in soils: a phosphate adsorbent and a source of available phosphorus. Geoderma 276:1-6. https://doi.org/10.1016/j.geoderma.2016.04.020

\section{Figures}




\section{Figure 1}

Schematic diagram of rhizobox experiment. (a) Placement of a group of rhizoboxes stacked at an angle of $60^{\circ}$ in the greenhouse; (b) Example rhizobox with effective size of $40 \mathrm{~cm} \times 30 \mathrm{~cm} \times 0.6 \mathrm{~cm}$.

\section{Figure 2}

LangmuirEXT1 model fitting to the growth of roots in different treatments for 10 weeks. (a) For total root growth in each sample; (b) For TA3 root growth in each sample. Data used for model fitting are the mean of replicates.

\section{Figure 3}

Kernel Density $\left(\mathrm{cm}^{2}\right)$ of summarized new roots in different treatments. (a) Blank; (b) TSP fertilizer; (c) Processed biochar; (d) Reference biochar; (e) VCZ biochar. Data used for Kenral Density are the new roots across five replicates of each treatment after 10 weeks experimental period.

\section{Figure 4}

Cumulative weekly root density difference between TA3 and corresponding areas on the opposite side of the rhizobox for 10 weeks. A positive number means that the density in TA3 was greater, while a negative number means density in TA3 was lower. The larger/lower the number, the greater the new root growth in TA3/opposite side. Data are mean $\pm S E, n=5$ except for Blank where $n=4$.

\section{Figure 5}

(a) Available $P$ reduction in treated areas after 10 weeks, $p<0.05$. Data are mean $\pm S E, n=3$ for original samples, $\mathrm{n}=5$ for samples after 10 weeks except for Blank where $\mathrm{n}=4$; (b) The total content of $\mathrm{Ca}, \mathrm{Fe}, \mathrm{Al}$ in TA after application on a logarithmic scale. Data are mean $\pm S E, n=3$, SE comes from 3 replicates of original samples. $n=5$ in the Blank.

\section{Supplementary Files}


This is a list of supplementary files associated with this preprint. Click to download.

- ESM1.docx.docx

- ESM2.xIsx.xIsx 